\title{
Sélection récurrente chez les autogames pour l'amélioration des variétés lignées pures: une revue bibliographique. II
}

\author{
MINISTERE de L'AGRICULTTURE
}

STATION de GENETIQUE

et D'AMELIORATION des PLANTES

INRA B.V. 1540

I Goldringer 1, P Brabant 1, 2

21034 DIJON CEDEX

FRANCE

1 INRA, station de Génétique végétale, ferme du Moulon, F91190 Gif-sur-Yvette ;

2 INA-PG, 16, rue Claude-Bernard, F75005 Paris, France

(Reçu le 23 mars 1993 ; accepté le 20 mai 1993)

\begin{abstract}
Résumé - Des schémas de sélection récurrente, proches de ceux utilisés dans l'amélioration des espèces allogames, ont maintenant été appliqués à de nombreuses espèces autogames. Une revue bibliographique de ces expériences s'arrêtant aux articles parus en 1989 (Kervella et al, 1991) a permis d'en montrer la faisabilité ainsi que l'intérêt pour l'amélioration de la valeur en lignée. Cependant, de nombreux points restaient à optimiser : intercroisement, sélection précoce et prise en compte de l'aspect multicaractère. Nous présentons ici une revue complémentaire portant principalement sur les articles parus de 1990 à 1992, mais revenant également sur quelques articles plus anciens non cités dans la première revue. Une évolution dans l'approche, les méthodologies et les préoccupations des expérimenteurs est mise en évidence. L'efficacité des schémas est évaluée ; les problèmes encore rencontrés ainsi que les limites des expériences sont discutés.
\end{abstract}

sélection récurrente / espèces autogames / progrès génétique / valeur en lignée

Summary - Recurrent selection for breeding self-pollinated species as pure line varieties: a review. II. Recurrent selection schemes close to those applied to cross-pollinated species have now also been largely used with autogamous species. Kervella et al (1991) made a bibliographic review of the experiments, covering papers published up to 1989. The feasibility of recurrent selection and the interest of applying it to pure line value breeding was demonstrated. Yet a number of different points still had to be optimized: intercrossing, early generation selection and multitrait selection. A complementary review which takes into account papers from 1990 to 1992 is presented here. Some older papers which did not appear in the first review are also analyzed. An evolution in the approaches, the methodologies and concerns of the authors is emphasized. Scheme efficiency is assessed; problems which remain to be solved and the limits of the experiments are discussed.

recurrent selection / autogamous species / genetic gain / pure line value

\section{INTRODUCTION}

À la suite de la revue bibliographique de Kervella et al (1991) qui s'arrête aux articles parus en 1989 , nous présentons une synthèse complémentaire couvrant principalement la période allant de 1990 à 1992. Quelques articles plus anciens non pris en compte dans la revue précédente figurent également dans cette synthèse. $\dot{A}$ travers cette nouvelle étude, nous avons cherché à mettre en évidence l'évolution dans les approches et dans les méthodologies des expérimentateurs. Les progrès dans l'effi- cacité générale des schémas ainsi que les problèmes encore rencontrés sont soulignés. Nous reprenons le canevas de la revue précédente : analyse des différentes modalités d'application de la sélection récurrente et évaluation des résultats.

Depuis 1989, la littérature relatant des expériences de sélection récurrente sur des espèces autogames a été particulièrement foisonnante. On peut y noter une certaine évolution dans l'approche des expérimentateurs. La plupart se placent dans un contexte où la faisabilité et même l'efficacité de la sélection récurrente 
appliquée aux espèces autogames ont été démontrées (Xu et Wilcox, 1992; Marocco et al, 1992). Ils cherchent maintenant à en optimiser certains points : sélection précoce (Branson et Frey, 1989a et b ; Schipper et Frey, 1991a), utilisation de la stérilité mâle (Tinius et al, 1991; Burton et al, 1990), sélection multicaractère (Matzinger et al, 1989; McFerson et Frey, 1991). D'autres auteurs utilisent un schéma de sélection récurrente pour comprendre les relations entre des caractères plus physiologiques, et proposent des systèmes de sélection indirecte (Carter et al, 1982 ; May et Van Sanford, 1992).

\section{REMARQUES PRÉLIMINAIRES}

La structure des tableaux récapitulatifs I et II est identique à celle utilisée dans la revue précédente (Kervella et al, 1991). Nous avons ajouté dans le tableau III les unités sur lesquelles se faisait l'évaluation du progrès. L'évaluation nous semble, en effet, un point critique majeur dans la plupart des expériences. Le nombre de cycles réalisés a également été inséré.

Certains articles reprennent un programme déjà décrit dans la première revue (Thomas et $a l, 1991 \mathrm{a}$ et $b$; Brabant et al, 1991 ; Marocco et al, 1992 ; Carter et al, 1982 ; Guimaraes et Fehr, 1989). Ils présentent alors l'intérêt d'une évaluation plus poussée (matériel plus fixé, caractères mesurés plus nombreux, conditions d'essais plus conformes à celles de la grande culture) ou évaluent un plus grand nombre de cycles. D'autres relatent des expériences partant de matériel extrait de populations déjà utilisées (Burton et al, 1990 : population PII ; Hanson, 1985 et 1992). Dans ce cas, la référence (code utilisé dans la revue précédente) est spécifiée dans les «lignées parents» du tableau I. La formation de certaines populations de soja a été décrite en détail par Burton et Brim (1981) ; il s'agit des populations référencées N79.1400 et N79.1500.

\section{APPLICATION DES PRINCIPES DE LA SÉLECTION RÉCURRENTE}

\section{Choix du matériel végétal et création de la population de base (tableau I)}

On peut remarquer tout d'abord une diminution du nombre d'espèces travaillées avec un recen- trage sur le soja. En particulier, les expériences sur le blé et l'orge sont devenues plus rares. $\mathrm{Pa}-$ rallèlement, on observe un développement de l'utilisation de stérilités mâles chez le soja. La présence d'un gène de stérilité mâle dans une population en sélection récurrente facilite l'intercroisement des individus sélectionnés. Pour le soja, la stérilité mâle génique présente un avantage certain, car les croisements manuels sont difficiles à réaliser. Des gènes de stérilité mâle sont disponibles pour la plupart des autres espèces présentées ici (Deng et Gao, 1982, in Saur et Trottet, 1992 ; Leemans, 1992) mais ne sont pas utilisés. Les expérimentateurs ont pu renoncer face à la difficulté à gérer le système (Kervella et al, 1991). L'évaluation du rendement en grains en parcelles, fréquente chez les céréales à paille, est en effet rendue difficile par la disjonction des familles pour la stérilité.

Tous les gènes de stérilité mâle utilisés sont récessifs. Sorrells et Fritz (1982) ainsi que Knapp et Cox (1988) présentent un certain nombre de schémas théoriques basés sur l'utilisation d'un gène de stérilité mâle dominant. Dans la pratique, de tels gènes ne sont disponibles que chez le colza, le blé et le coton. Saur et Trottet (1992) ont entamé une expérience de sélection récurrente avec stérilité mâle génique dominante, pour améliorer la résistance à la fusariose de l'épi du blé tendre d'hiver ; l'évaluation d'un cycle n'a pas encore été réalisée.

Sur les 21 populations utilisées comme départs des schémas de sélection récurrente, seules 3 ont été formées à partir de 2 parents (May et Van Sanford, 1992: population P1 ; Carter et al, 1982: population Pl; Matzinger et al, 1989). Les autres sont issues, pour la plupart, du croisement de 5 à 10 parents; seules 7 populations ont une base génétique plus large (Branson et Frey, 1989a; May et Van Sanford, 1992 : population P2 ; Thomas et al, 1991a; Guimaraes et Fehr, 1989 ; Hanson, 1985 ; Rose et al, 1992 ; Burton et al, 1990: population PII). Même les programmes utilisant une stérilité mâle ne partent pas d'un nombre de parents plus élevé (Tinius et al, 1991 ; Burton et al, 1983 ; Werner et Wilcox, 1990 ; Xu et Wilcox, 1992). On observe donc une certaine homogénéisation du nombre de lignées de départ (entre 5 et 10) sur l'ensemble des programmes, quelles que soient les modalités d'intercroisement.

En général, l'utilisation d'origines "exotiques" pour les parents est très limitée: on trouve un géniteur de tabac de mauvaise valeur agronomi- 
que présentant une résistance à Phytophthora parasitica (Legg et Nielsen, 1992), et quelques géniteurs non adaptés aux conditions de la zone de sélection comme les mâle-stériles de soja dans les programmes de Tinius et al (1991), Burton et al (1983 et 1990), ou une variété naine d'orge chez Marocco et al (1992). Seule, une population d'avoine a été formée à partir de groupes de génotypes d'origines très diverses (Branson et Frey, 1989a et b : Schipper et Frey, 1991b et 1992). Rose et al (1992), sur le soja, travaillent également sur une population d'origine géographique diversifiée, mais tous les génotypes présentent un bon niveau de rendement.

À la lecture des articles récents, il apparaît que les expérimentateurs ont surtout fait porter leur efforts sur l'intercroisement des parents. Celui-ci est devenu plus poussé : peu se contentent d'un croisement simple (May et Van Sanford, 1992 ; Carter et al, 1982). Matzinger et al (1989) pratiquent un deuxième brassage entre les F2 issues du croisement des 2 parents. Pour assurer plus de recombinaisons, certains réalisent 2 diallèles à la suite (Frey et al, 1988; Delaney et Bliss, 1991a) ou un diallèle suivi de 2 générations de croisements simples pour Rose et al (1992). D'autres combinent des générations d'intercroisement avec des générations de sélection (Branson et Frey, 1989a; Burton et al, 1983) ou font suivre les croisements simples entre parents d'un diallèle (Frey et al, 1988; Marocco et al, 1992 ; Tinius et al, 1991) ou/et de plusieurs générations d'intercroisement (Burton et al, 1990 ; Tinius et al, 1991). Ils sont alors aidés par un gène de stérilité mâle. Dans ces expériences, la stérilité mâle répond donc au problème de l'efficacité du brassage génétique et permet d'approcher la panmixie. Elle n'est pas utilisée pour augmenter la taille de la base génétique de départ, comme c'était le cas dans certaines expériences plus anciennes (Dogget, 1972 ; Habgood et Rafique Uddin, 1984).

\section{Sélection (tableau II)}

Dans un schéma de sélection récurrente, l'efficacité de la sélection dépend de la durée du cycle et donc de la précocité de la sélection. Elle dépend également de la variabilité génétique sur laquelle elle agit (nombre et type d'individus), de l'intensité appliquée (nombre d'individus observés et nombre d'individus gardés) et, dans le cas de sélection pour la valeur en lignée, de la cova- riance entre valeur en test et valeur en lignée des descendants, le tout devant être géré de façon à ce que l'efficacité se maintienne à long terme (maintien de la variabilité génétique). Pour certains caractères sélectionnés, il est nécessaire d'effectuer le jugement en parcelles et d'avoir suffisamment de semences (sélection sur familles) pour être le plus proche possible des conditions de la grande culture. De plus, pour obtenir du matériel agronomique intéressant, il faut souvent prendre en compte un ensemble de caractères et non un seul. L'optimisation de l'efficacité d'un schéma consiste donc à combiner ces différentes conditions, souvent antagonistes. Il semble que le premier point sur lequel un grand nombre d'expérimentateurs se rencontrent soit la précocité de sélection et un cycle très court.

En effet, dans tous les programmes, la sélection est devenue très précoce $\left(S_{0}\right.$ ou $\left.S_{1}\right)$. Hanson (1992) sélectionne en $S_{2}$, et seuls Guimaraes et Fehr (1989), qui reprennent les résultats du programme déjà présenté par Piper et Fehr (1987), sélectionnent en $S_{3}$ ou $S_{4}$. La plupart des schémas tiennent en 1 an ou 2 ; seuls 2 schémas sur le blé et l'orge (Thomas et al, 1991b; Brabant et al, 1991; Marocco et al, 1992) durent 3 ans. La sélection y est faite en deux temps: sur plantes $S_{0}$, puis sur familles $S_{1}$, et l'intercroisement prend une année supplémentaire. Guimaraes et Fehr (1989) travaillent également sur des schémas de 3 à 4 ans.

De nombreux expérimentateurs effectuant une sélection en $S_{1}$ font pousser les plantes $S_{0}$ en serre à l'issue de l'intercroisement, sans pratiquer de sélection, et obtiennent les semences $S_{1}$ pour le printemps (Frey et al, 1988; McFerson et Frey, 1990, 1991 et 1992 ; Delaney et Bliss, 1991a et 1991b; Tinius et al, 1991 et 1992 ; Burton et al, 1990). Ce système permet de sélectionner en 1 an sur des familles $S_{1}$, qui constituent théoriquement le niveau de sélection pour la valeur en lignée le plus efficace après les lignées haploïdes doublées (Gallais, 1990). Le fait d'accélérer la génération $S_{0}$ en serre présente cependant l'inconvénient de ne pas permettre de sélection à ce niveau.

Hanson (1992), sur le soja, fait tenir un cycle avec sélection sur $S_{2}$ en 1 an. L'intercroisement puis 2 autofécondations sont pratiquées en serre pendant l'hiver. Cependant, pour limiter le nombre d'individus à mener jusqu'en $S_{2}$, les familles de demi-frères (HS) issues de l'intercroisement sont autofécondées en bulk jusqu'à la 


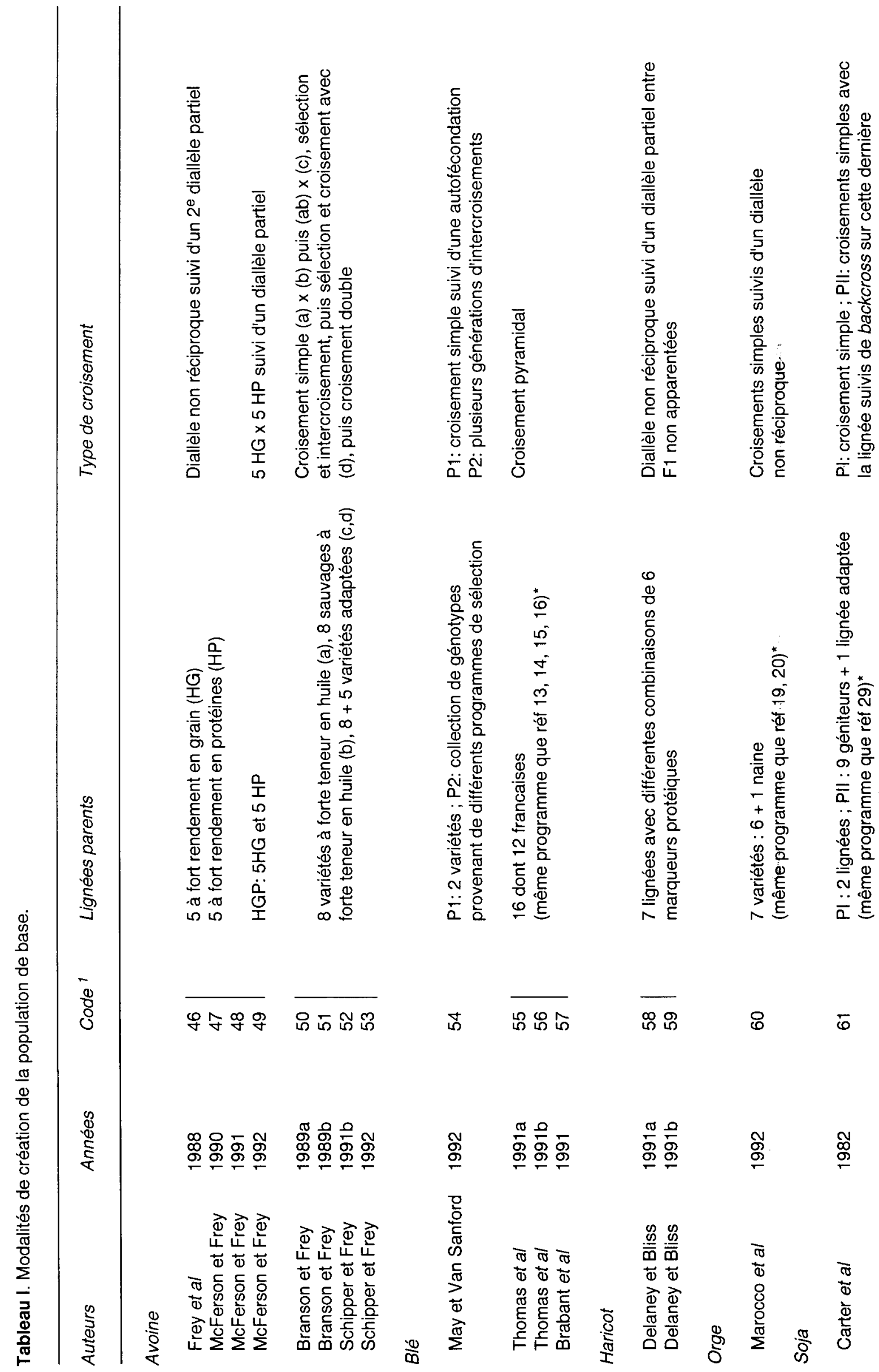



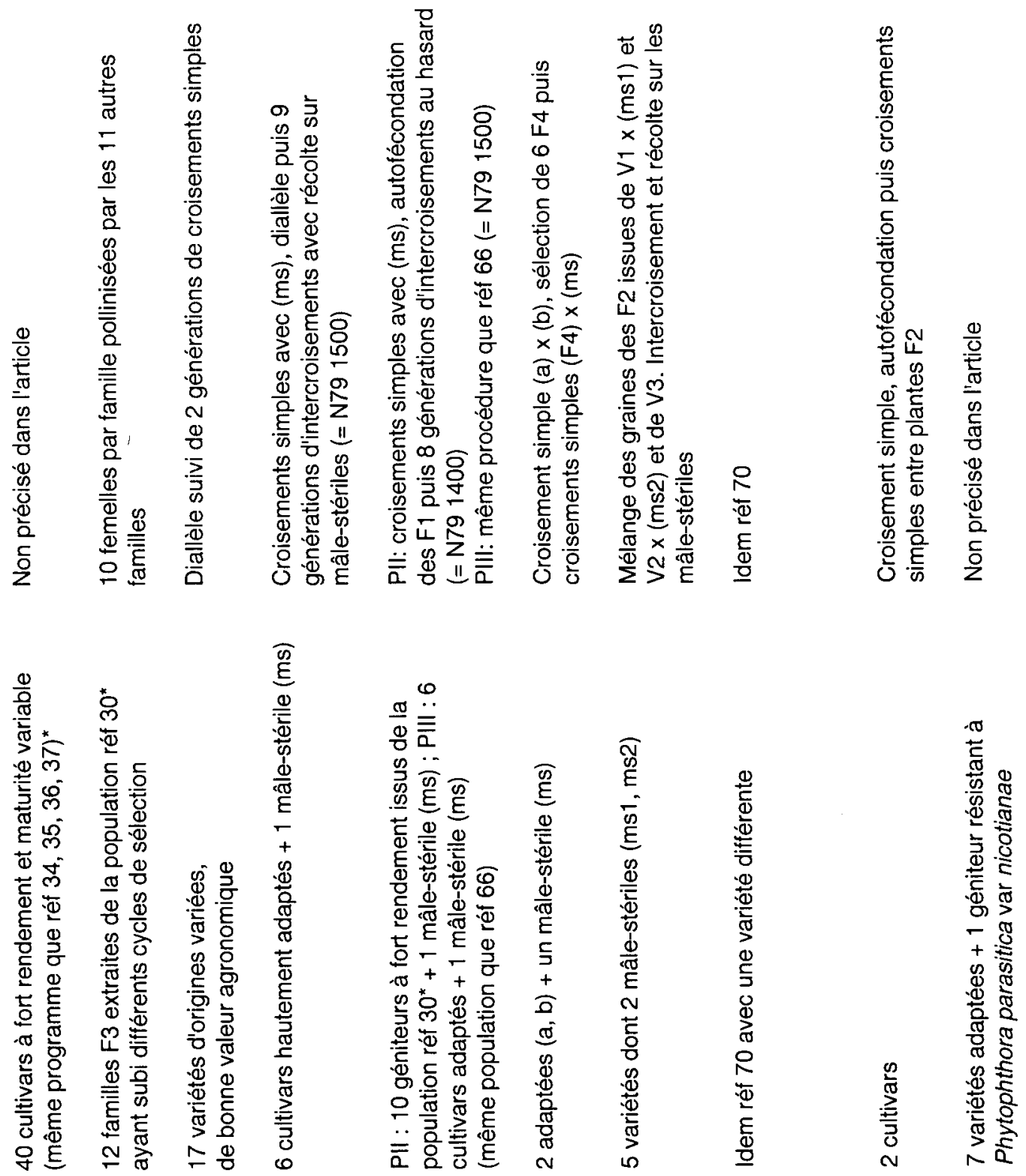

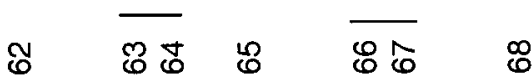

$8 R$

$\stackrel{1}{\mathfrak{N}}$

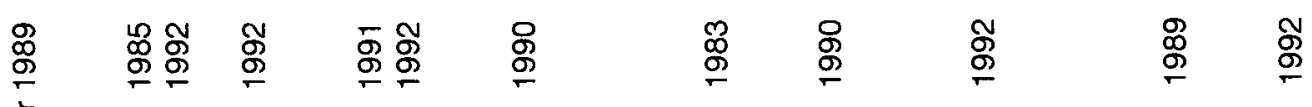

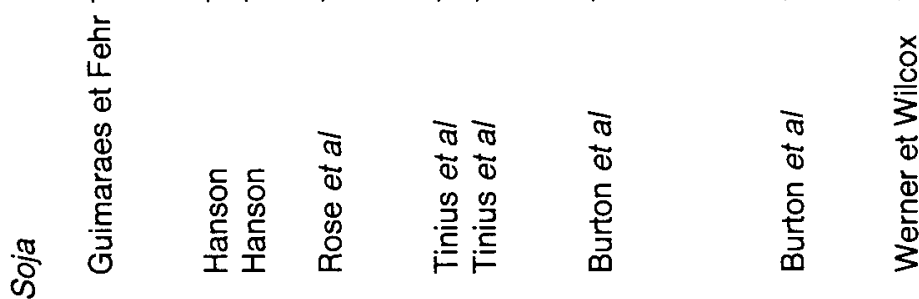

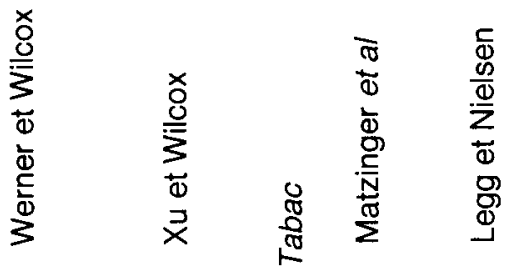

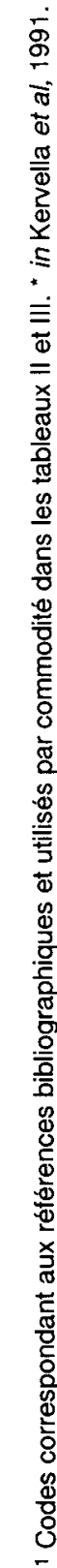




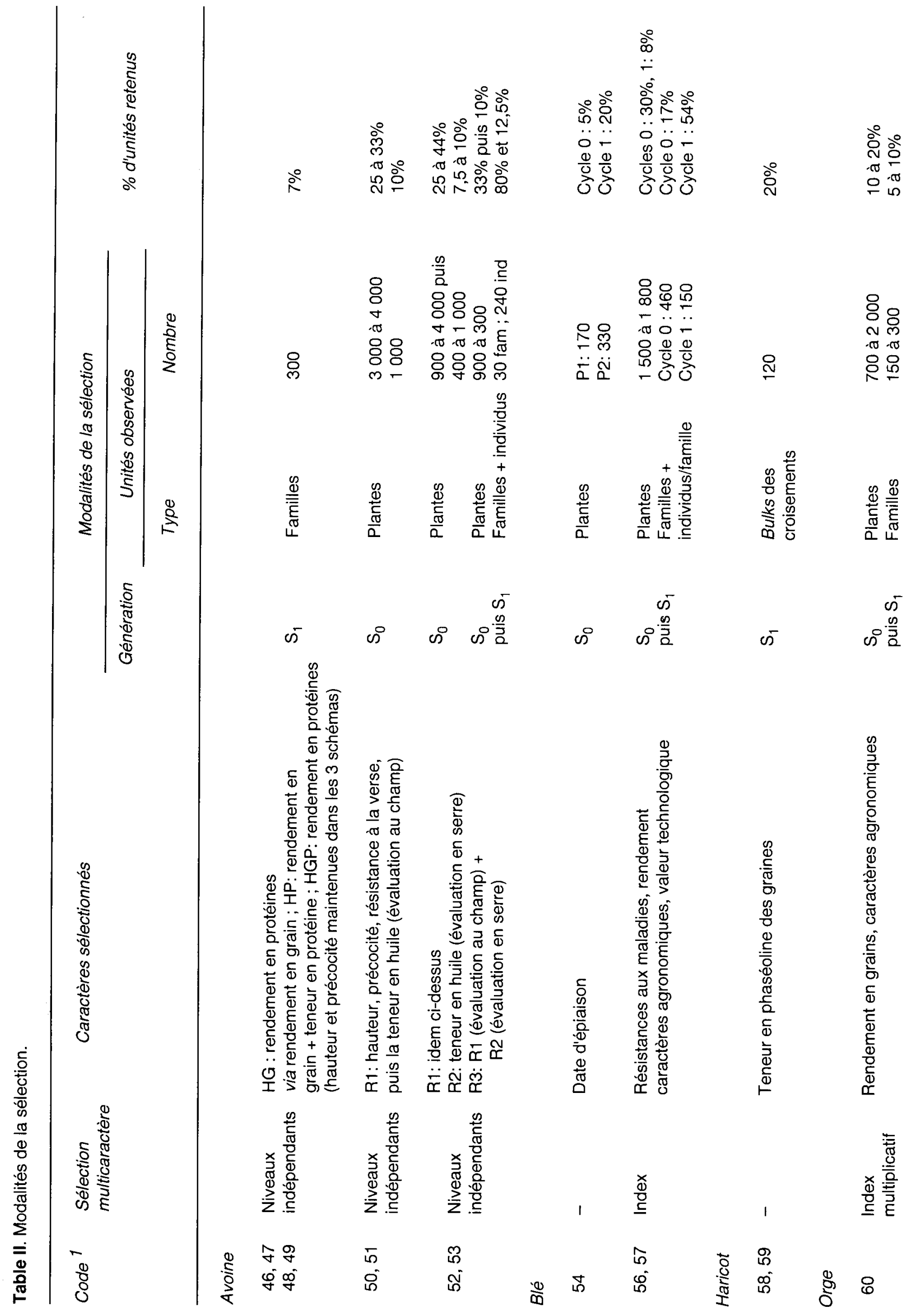




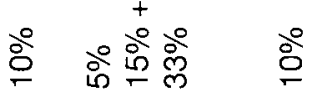

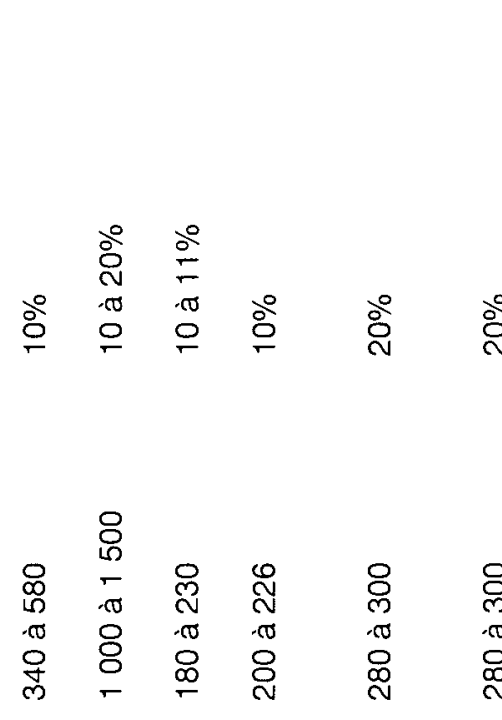

৪

응 유윰요 음

今े

흠

$\frac{\sqrt{2}+2}{2}$

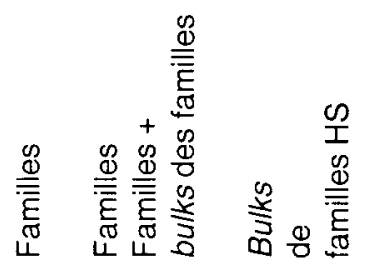

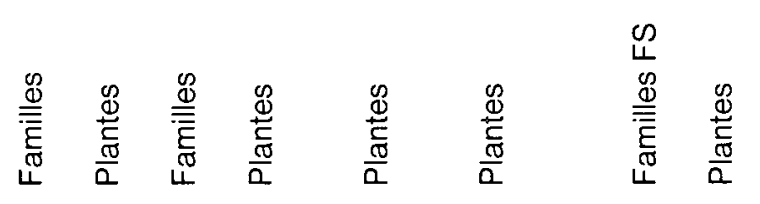
ஸึल

$\dot{\mathrm{N}} \ddot{\Sigma} \dot{\mathrm{v}}$

का $\sum^{\Sigma} \sum^{\infty} \omega^{+}$का

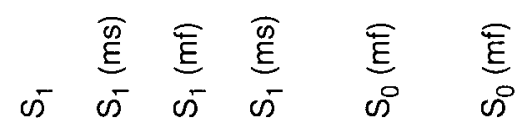

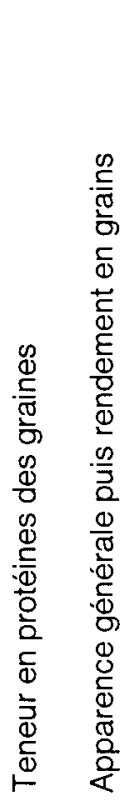

$\stackrel{\oplus}{\oplus}$

$\stackrel{8}{\frac{\Phi}{5}}$

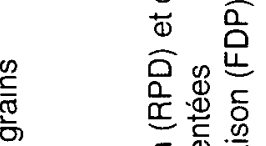

๘ $\quad$ 은 है

है

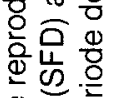

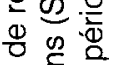

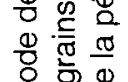

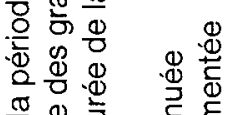

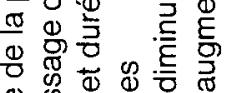

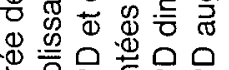

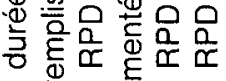

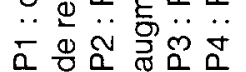

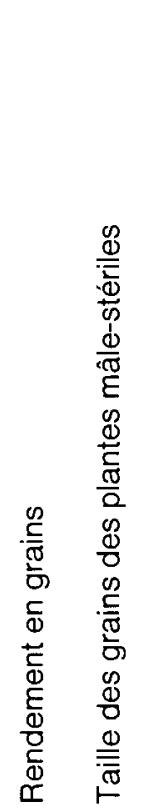

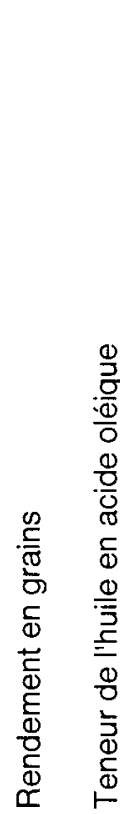

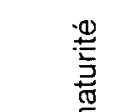
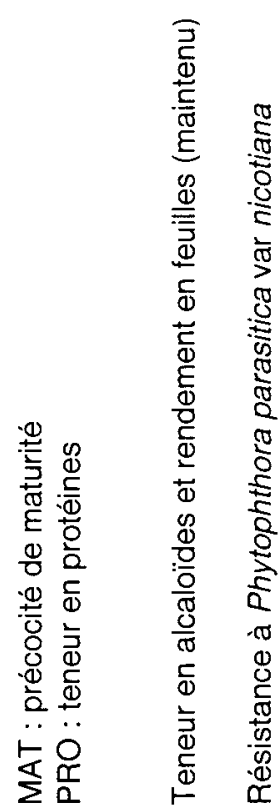

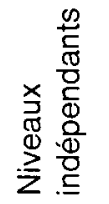

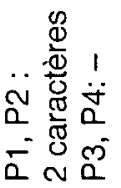

के $\overline{0}$

घั

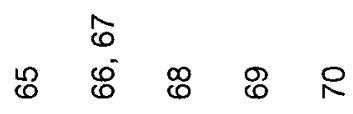

र $\frac{\sqrt{8}}{\pi} \sqrt{8}$

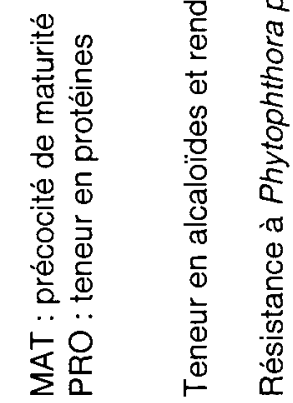

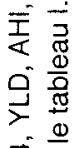

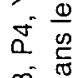

穴.

등 
$\mathrm{S}_{2}$. La sélection peut alors sembler difficile, car elle s'effectuera sur des unités très hétérogènes (bulks $\mathrm{S}_{2}$ de familles $\mathrm{HS}$ ) et agira sur une variance génétique entre les bulks limitée.

Sur la période couverte, on ne trouve aucune expérience de sélection récurrente utilisant I'haplo-diploïdisation. Cette méthode permet pourtant de sélectionner sur des lignées pures. L'intérêt théorique de l'utilisation de I'haplodiploïdisation en sélection récurrente a été démontré (Gallais, 1990) et de nombreux schémas ont été proposés (Choo et al, 1979; Gallais, 1990). La possibilité d'obtenir par haplodiploïdisation du matériel utilisable en sélection a été démontrée expérimentalement : pas (ou peu) de déviation de la distribution génotypique observée à la distribution espérée et pas d'effets apparents de variation gamétoclonale (Snape et al, 1992 ; Suenaga et Nakajima, 1993). Cependant, aucune nouvelle expérience de sélection récurrente basée sur l'haplo-diploïdisation n'a été recensée depuis Patel et al (1985). Plusieurs explications peuvent être données. Les techniques d'haplo-diploïdisation (culture d'anthères, de microspores ou croisements interspécifiques) ne sont pas maîtrisées pour toutes les espèces considérées ici. Pour celles pour lesquelles I'haplo-diploïdisation est au point, l'efficacité dépend du matériel génétique mené en sélection récurrente et les expérimentateurs peuvent craindre de sélectionner surtout sur l'aptitude à répondre à la méthode utilisée. La production en grande quantité ou même en faible quantité mais avec des exigences sur la structuration (une lignée par croisement, par exemple) nécessite un volume de travail important. Pour d'autres espèces, l'accélération des cycles d'autofécondation permet d'obtenir rapidement du matériel à haut niveau de fixation (Hanson, 1992).

Lorsque la sélection opère en $S_{0}$, il s'agit généralement d'une sélection massale individuelle, sauf pour Matzinger et al (1989) qui observent des familles de plein-frères. La sélection porte souvent sur un seul caractère, mais Branson et Frey (1989a et b) pratiquent une sélection par niveaux indépendants pour un caractère principal associé à des caractères agronomiques de base. Pour les autres expériences, les caractères sélectionnés sont une résistance à un agent pathogène (Legg et Nielsen, 1992), des caractères physiologiques ou morphologiques (Matzinger et al, 1989 ; Branson et Frey, 1989a et $b$; May et Van Sanford, 1992 ; Xu et Wilcox, 1992), et même le rendement en grains (Werner et Wilcox, 1990). Les plantes sont semées en plantes isolées et donc en conditions très éloignées des conditions de grande culture. La plupart des espèces considérées ici étant affectées par la densité et la compétition (Jacquard, 1975 ; Stelling et al, 1990), on peut se demander si les caractères sélectionnés, de type morphologique, de développement ou de rendement, ne sont pas éloignés de leurs équivalents en conditions normales de culture.

Si la sélection opère sur des caractères non liés aux semences, elle peut se faire avant la fécondation, et l'intercroisement se fait alors directement entre unités sélectionnées (May et Van Sanford, 1992 ; Legg et Nielsen, 1992). Cela permet d'accélérer le cycle mais constitue un cas d'école plutôt qu'un schéma réellement utilisable en sélection.

Les auteurs ne semblent pas exploiter au mieux les avantages de la sélection en $\mathrm{S}_{0}$. À part Branson et Frey (1989a et b) qui évaluent 3000 à 4000 plantes, les autres en observent des quantités relativement faibles: May et Van Sanford (1992) observent 170 ou 330 plantes, Werner et Wilcox (1990) et Xu et Wilcox (1992) en observent 300 et Matzinger et al (1989) 120. L'intensité de sélection appliquée n'est, de ce fait, pas plus forte que celles pratiquées dans les autres schémas. Branson et Frey (1989a et b), qui sélectionnent pour la teneur en huile (caractère difficile et coûteux à évaluer), effectuent un premier tri sur des caractères agronomiques plus simples à mesurer.

La sélection au niveau $S_{1}$ (ou $S_{2}$ ) utilise généralement la structuration en familles autofécondées, sauf chez Delaney et Bliss (1991a et b) et Hanson (1992) où les familles issues de plantes $S_{0}$ provenant d'un même croisement sont regroupées en bulks. Les problèmes qui apparaissent dans ce cas ont déjà été discutés plus haut pour Hanson (1992). La sélection n'est pas non plus familiale dans les schémas avec stérilité mâle (Tinius et al, 1991 et 1992 ; Burton et al, 1983) où les plantes sont observées individuellement. Dans le cas général, la sélection se fait sur les valeurs familiales, suivies éventuellement d'un choix intrafamilles (Schipper et Frey, 1991b et 1992 ; Thomas et al, 1991b ; Brabant et al, 1991).

La sélection familiale (ou sur bulks) permet d'évaluer le rendement en parcelle et non en plantes isolées. Cependant, dans les schémas avec stérilité mâle, comme on l'a vu plus haut, il y a ségrégation pour le gène de stérilité dans les familles autofécondées. Burton et al (1990) prati- 
quent quand même une sélection familiale pour le rendement: seules les plantes fertiles sont récoltées et participent à la valeur de la famille. Cependant, cette procédure nécessite de pouvoir individualiser les plantes dans la parcelle, ce qui est impossible chez les céréales à paille, à moins de repasser en plantes isolées. Cela contribue à justifier l'absence d'utilisation de stérilités mâles dans les schémas appliqués aux céréales.

Bien que de nombreux auteurs se concentrent encore sur la sélection d'un seul caractère, ils sont de plus en plus nombreux à s'intéresser à la valeur agronomique générale des individus sélectionnés. On observe quelques exemples de sélection multicaractère. Pour l'avoine, tous les schémas sont basés sur une sélection par niveaux indépendants ; on cherche à améliorer un caractère principal complexe (rendement en protéines, teneur en huile) tout en maintenant des caractères agronomiques classiques au niveau de la population de départ. Guimaraes et Fehr (1989) font de même avec le rendement en grain sur le soja. D'autres auteurs ne s'attachent qu'à un second caractère en plus du principal, soit en sélectionnant par niveaux indépendants (Matzinger et al, 1989), soit en corrigeant le second par le premier (Werner et Wilcox, 1990). Deux expériences seulement sont basées sur un index: Thomas et al (1991b) et Brabant et al (1991) sur le blé, et Marocco et al (1992) sur l'orge. Les 2 schémas sont similaires par de nombreux points, mais l'index appliqué à la population de blé est additif classique, alors que celui appliqué à la population d'orge est multiplicatif et semble moins complet : les résistances aux maladies et la qualité ne sont pas prises en compte.

\section{Intercroisement des familles sélectionnées}

Dans 2 cas évoqués plus haut (May et Van Sanford, 1992 ; Legg et Nielsen, 1992), l'intercroisement se fait entre les unités sélectionnées, car la sélection a lieu avant fécondation. Lorsque la sélection opère sur des individus $S_{1}$ mâle-stériles (Burton et al, 1983), ce sont aussi les unités évaluées qui sont directement intercroisées. Mais l'intercroisement (pollinisation par l'ensemble des plantes mâle-fertiles) a lieu avant la sélection. Dans ce cas, le progrès attendu est divisé par 2 par rapport à un schéma avec sélection sur les 2 parents. Cette perte est compensée par un gain de temps par rapport à un schéma comme celui pratiqué par Marocco et al (1992) et Matzinger et al (1989), où les unités sélectionnées (familles $S_{1}$ dans le premier cas, familles de plein-frères dans le second) sont intercroisées grâce au semis de graines conservées.

Dans les autres cas, l'intercroisement a lieu entre les descendances des unités sélectionnées. II n'est pas toujours facile d'identifier entre quelles unités se font les croisements. Dans le cas des sélections sur $S_{0}$, l'intercroisement se fait entre les familles $S_{1}$ issues des plantes sélectionnées (Branson et Frey, 1989a et b; Schipper et Frey, 1991b et 1992 : régimes R1 et $\mathrm{R} 2$ ). La présence d'un gène de stérilité mâle permet de réaliser un intercroisement complet des familles: les individus $S_{1}$ sont mélangés au semis et la récolte se fait sur les mâle-stériles (Werner et Wilcox, 1990 ; Xu et Wilcox, 1992). Lorsqu'il s'agit d'une sélection sur $S_{1}$, soit les croisements se font entre familles $S_{2}$ issues de plantes $S_{1}$ (Thomas et al, 1991b ; Brabant et al, 1991 ; Schipper et Frey, $1991 \mathrm{~b}$ et 1992 : régime R3) ou bien entre bulks $S_{2}$ issus des familles $S_{1}$ sélectionnées (Frey et al, 1988; McFerson et Frey, 1990, 1991 et 1992 ; Rose et al, 1992).

Pour gagner du temps, de nombreux auteurs effectuent l'intercroisement en génération dérobée, en serre pendant l'hiver ; pour les espèces à semis d'automne, c'est impossible et la durée du cycle s'en ressent (Thomas et al, 1991b ; Brabant et al, 1991 ; Marocco et al, 1992).

L'intercroisement des familles hétérogènes $\left(S_{1}\right.$ ou $\left.S_{2}\right)$ est souvent réalisé avec plusieurs plantes par famille. Cela permet à la fois de croiser chaque famille avec plusieurs autres et de mieux représenter la famille qui est encore très variable à ce niveau. Généralement, lorsque le nombre d'individus sélectionnés diminue, les croisements entre ces individus deviennent plus nombreux. S'ils ne disposent pas d'une stérilité mâle dans la population, les expérimentateurs croisant plus d'une cinquantaine d'individus font de 1 à 6 croisements par individu (Branson et Frey, 1989a et b; Schipper et Frey, 1991 b et 1992 ; May et Van Sanford, 1992 ; Thomas et al, 1991b ; Brabant et al, 1991 ; Legg et Nielsen, 1992). Les autres croisent de 10 à 20 familles grâce à un diallèle plus ou moins partiel. Là encore, les utilisateurs de stérilité mâle ne l'utilisent pas pour croiser un plus grand nombre d'individus (au maximum 60 à 80 chez Werner et Wilcox [1990] et Xu et Wilcox [1992]), mais plutôt pour les intercroiser plus efficacement.

On peut noter ici que les résultats de Guimaraes et Fehr (1989) confirment ceux précédemment obtenus par Piper et Fehr (1987) : 3 géné- 
rations d'intercroisement ne présentent pas d'avantage sur la stratégie classique d'un seul intercroisement.

L'ensemble des observations faites sur l'application des principes de la sélection récurrente aux espèces autogames se résume en quelques points. L'effort des expérimentateurs a porté sur la durée du cycle; la sélection est devenue très précoce et la maîtrise des générations dérobées (intercroisement ou $\mathrm{S}_{0}$ ) a permis également un fort gain de temps. II faudra cependant vérifier que la sélection en génération précoce a bien permis un progrès sur le caractère en conditions de culture commerciale. Pour cela, nous insisterons sur les conditions d'évaluation du progrès. Par ailleurs, nous avons vu que la base génétique de départ s'est centrée autour de 5 à 10 individus, et que le nombre d'individus sélectionnés est souvent compris entre 10 et 20 . Une observation de l'évolution de la variabilité génétique pourra donner une indication sur l'intérêt à long terme des schémas. On peut regretter que la prise en compte de l'aspect multicaractère ne soit pas plus répandue, mais il sera intéressant d'observer les réponses corrélatives qui ont été, en revanche, abondamment étudiées.

\section{RÉSULTATS OBTENUS}

\section{Évolution de la valeur moyenne de la population (tableau III)}

L'intérêt porté par les expérimentateurs aux réponses corrélatives entraînées par la sélection est double. Il s'agit souvent de vérifier que le niveau agronomique général des individus sélectionnés n'a pas baissé à cause d'une réponse fortement négative d'un caractère non pris en compte dans la sélection. Par ailleurs, certains auteurs sélectionnent de façon indirecte car le caractère qu'ils cherchent à améliorer est difficile à évaluer. Nous regrouperons dans une première partie l'étude du progrès sur les caractères "principaux" améliorés, de façon directe ou non, puis nous étudierons les réponses corrélatives «non recherchées" par les expérimentateurs.

\section{Réponse obtenue sur les caractères à améliorer}

Les auteurs évaluent toujours au moins 2 cycles de sélection sauf Guimaraes et Fehr (1989) sur le soja pour leur schéma le plus long, ainsi que
Thomas et al (1991b) et Brabant et al (1991) sur le blé. Trois ou quatre cycles sont fréquemment évalués, certains présentant même le progrès de 6 cycles (Schipper et Frey, 1991b et 1992 ; Carter et al, 1982). Lorsque 4 à 6 cycles sont étudiés, cela peut permettre de juger s'il y a maintien, ou non, du rythme du progrès.

La plupart des résultats montrent des réponses dans le sens attendu, mais certaines ne sont pas significatives. C'est le cas pour la réponse à la sélection pour la teneur en huile évaluée en serre chez l'avoine (Branson et Frey, $1989 \mathrm{a}$ et b), la réponse pour le rendement chez le blé (Thomas et al, 1991b ; Brabant et al, 1991) et chez le soja dans les stratégies M1 et M2 de Guimaraes et Fehr (1989) et dans la population III de Burton et al (1990), et enfin la réponse sur I'harvest-index du soja chez Werner et Wilcox (1990). Ces réponses non significatives sont souvent associées à des schémas complexes, comprenant des aspects multicaractères, de la sélection indirecte ou des étapes supplémentaires, sur lesquels nous reviendrons ultérieurement. L'absence de réponse à la sélection pour I'harvest-index chez le soja (Werner et Wilcox, 1990) sort pourtant dans ce cadre. En effet, la sélection est directe et ne prend que ce caractère en compte. Les auteurs justifient le résultat obtenu par une absence de variabilité génétique pour ce caractère : Wilcox et May (1986) in Werner et Wilcox (1990) estiment l'héritabilité de l'harvest-index à 0,11 au maximum, et la variabilité observée serait due principalement à des effets environnementaux.

Burton et al (1983) estiment après 4 cycles d'amélioration de la teneur en acide oléique du soja l'héritabilité de ce caractère à 0,21 , ce qui leur semble assez faible pour un schéma de sélection sur plantes $S_{1}$. On peut ici se demander si la sélection pratiquée sur plantes mâle-stériles est bien une sélection sur $S_{1}$. Si la teneur en acide oléique est une caractéristique de l'embryon, c'est une sélection sur familles de demifrères issus de $S_{1}$ qui est effectuée, et le progrès attendu est alors:

$$
\mathrm{i} \times \frac{3}{8} \times \frac{\sigma_{A}^{2}}{\sigma_{P H S\left(S_{1}\right)}}
$$

et non pas:

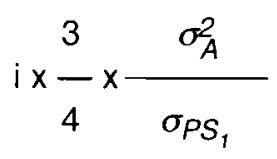


comme proposé dans l'article (avec $\sigma_{A}^{2}$ variance additive, $\sigma_{P S 1}^{2}$ variance phénotypique entre individus $S_{1}$ et $\sigma_{p H S\left(S_{1}\right)}^{2}$ variance phénotypique entre familles de demi-frères issus d'individus $S_{1}$ ).

Dans les schémas avec niveaux indépendants, les caractères agronomiques "annexes" sont généralement maintenus. Les schémas menés pendant 4 à 6 cycles ne semblent pas présenter de ralentissement du progrès. Schipper et Frey (1991b et 1992) pour leur régime R1 trouvent une réponse linéaire durant les 6 cycles, Tinius et al (1991 et 1992) ainsi que Xu et Wilcox (1992) également, mais pendant 4 cycles. Certains auteurs, n'ayant pourtant pas poussé la sélection jusqu'à 4 cycles, annoncent un progrès plus fort au premier. May et Van Sanford (1992) sont dans ce cas; il est cependant à noter qu'ils ont diminué l'intensité de sélection en passant du premier au second cycle (5\% et $20 \%$ d'individus sélectionnés). Pour les populations P1 et P2, Hanson (1992) observe un progrès plus fort au premier cycle, qu'il n'explique pas.

Lorsque les auteurs, pour améliorer un caractère, sélectionnent sur un autre (souvent composante du premier), les résultats sont encourageants. Frey et al (1988), McFerson et Frey (1990, 1991 et 1992) cherchent à améliorer le rendement en protéines par 3 méthodes différentes : en sélectionnant pour augmenter le rendement en grains, pour augmenter à la fois le rendement en grains et la teneur en protéines, et pour augmenter le rendement en protéines directement. II apparaît que la sélection pour le rendement en grains, associée à la teneur en protéines, entraîne le progrès maximal sur le rendement en protéines $(+5,3 \%)$. Elle permet de combiner 2 caractères (rendement et teneur en protéines) généralement antagonistes, auxquels la sélection directe ne donne pas accès. Hanson (1992) sur le soja et May et Van Sanford (1992) sur le blé, montrent que l'on peut modifier certains critères physiologiques complexes en agissant sur des caractères plus simples (date d'épiaison chez le blé), ou en contrôlant plusieurs composantes de la variable étudiée.

Deux expériences de sélection multicaractère avec index ont été réalisées. Marocco et al (1992) observent des progrès importants sur le rendement et la précocité d'épiaison, mais pas d'effet significatif sur la hauteur et le poids de 1000 grains. Les sélectionneurs ayant donné un poids beaucoup plus fort au rendement, la réponse prédominante sur celui-ci n'est pas surprenante. Dans le second cas, les évaluations de
Thomas et al (1991b) et Brabant et al (1991) s'accordent pour monter un progrès principalement sur les résistances aux maladies et aucun sur le rendement. Le nombre et la variété des caractères pris en compte dans la sélection peuvent justifier, au premier abord, des irrégularités au niveau des réponses, en particulier pour des caractères complexes comme le rendement. Avec des schémas multicaractères, plus le sélectionneur cherche à prendre en compte de caractères, plus il lui sera difficile d'obtenir un progrès sur tous, et plus celui-ci sera lent. Cependant, c'est bien la valeur agronomique globale qui importe.

Certains auteurs ont répété le même schéma sur 2 populations différant par leur base génétique. May et Van Sanford (1992) ainsi que Carter et al (1982) observent des réponses qualitativement semblables pour les 2 populations, celle de base génétique plus large présentant le progrès le plus important. Burton et al (1990) trouvent une réponse non significative pour le rendement dans la population III. Si l'on regarde plus en détail, il y a sans doute un progrès sur les 2 premiers cycles (+ $7 \%$ par cycle), annulé par une diminution de $9 \%$ au troisième. Bien que les nombres de géniteurs au départ des populations II et III soient comparables, les auteurs justifient l'absence de progrès dans la population III par un manque de variabilité génétique dès le départ: le coefficient de variation génétique de cette population est la moitié de celui de PII.

La comparaison des progrès calculés dans ces différentes expériences est cependant hasardeuse. En effet, la mesure des progrès dépend beaucoup des conditions d'évaluation. Tout d'abord, le matériel évalué diffère d'une expérience à l'autre. La plupart des expérimentateurs comparent des familles ou bulks $S_{1}$ à $S_{4}$ issus de familles prises au hasard dans chaque cycle. D'autres comparent les descendances bulks $S_{1}$ à $S_{4}$ des familles sélectionnées à chaque cycle (May et Van Sanford, 1992 ; Carter et al, 1982 ; Guimaraes et Fehr, 1989 ; Hanson, 1992 ; Burton et al, 1983). Certains utilisent des échantillons restant des individus $S_{0}$ ou des familles $S_{1}$ testés dans le schéma (Thomas et al, 1991b ; Delaney et Bliss, 1991a et b). Werner et Wilcox (1990) ainsi que Xu et Wilcox (1992) comparent les valeurs des individus $S_{0}$ de chaque cycle grâce à un témoin semé chaque année. Les progrès sont calculés par régression des moyennes $S_{0}$ relatives au témoin, à chaque cycle, sur le nombre de cycle. Matzinger et al (1989) intercroisent les familles de chaque cycle 


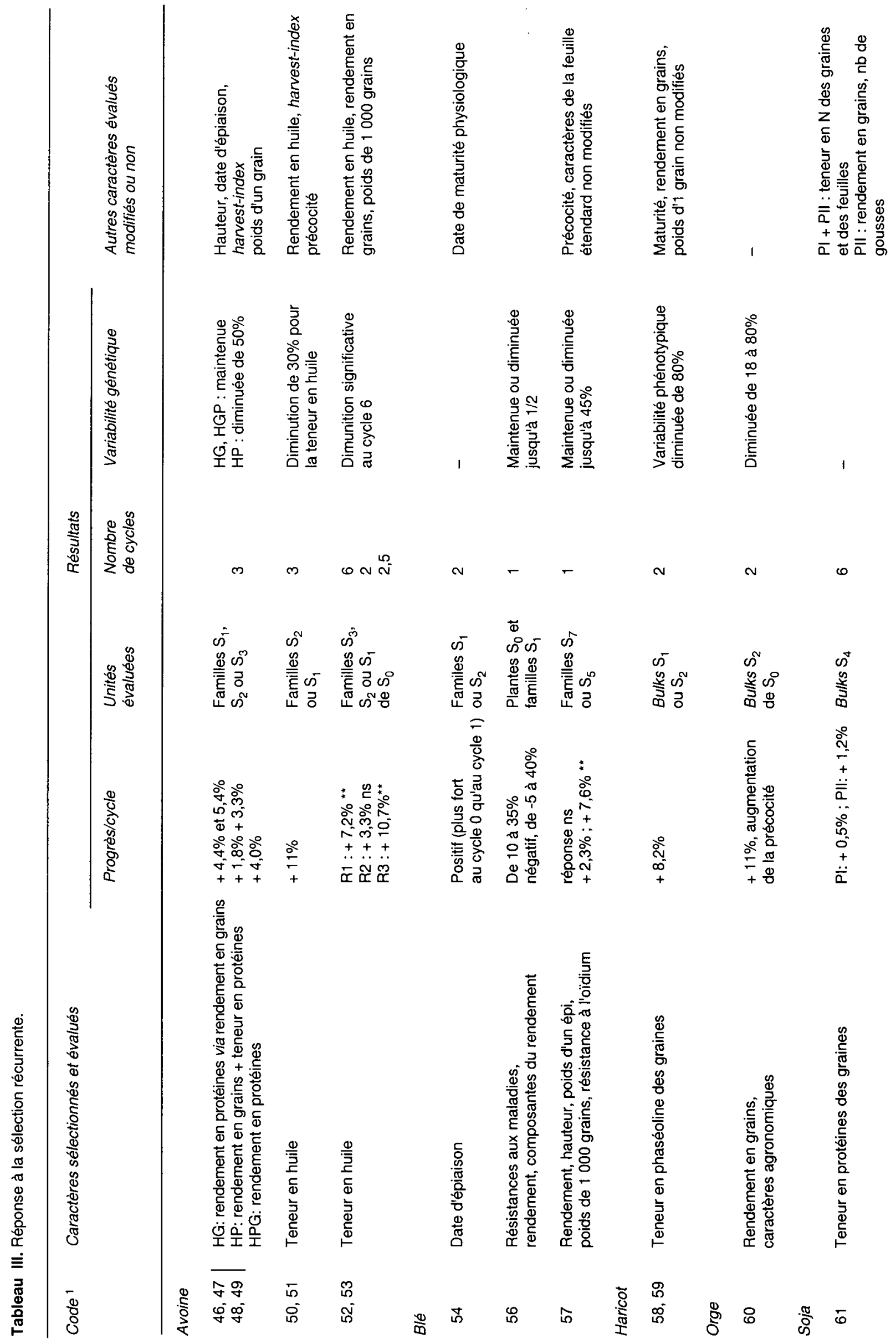



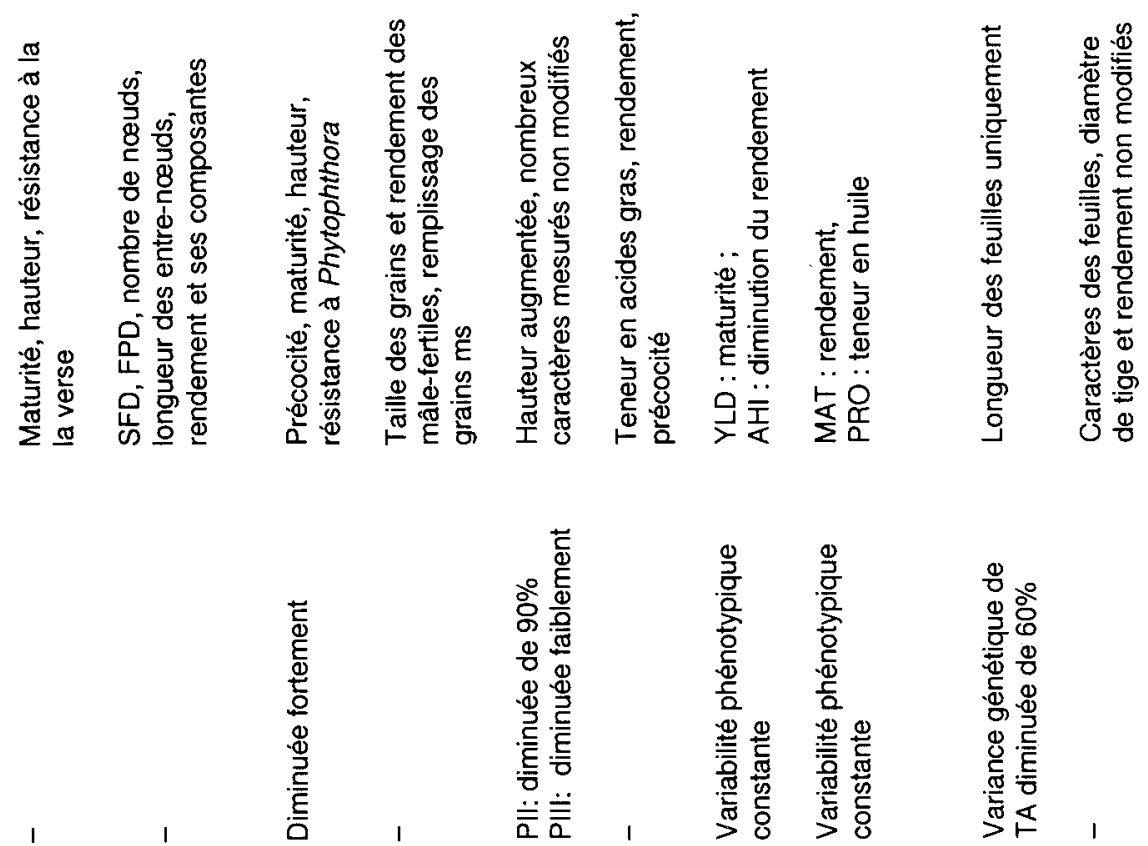

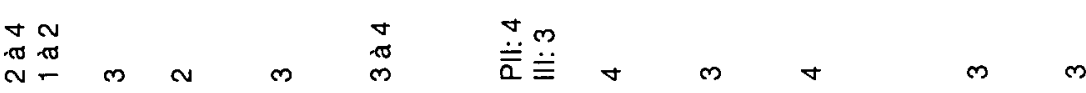

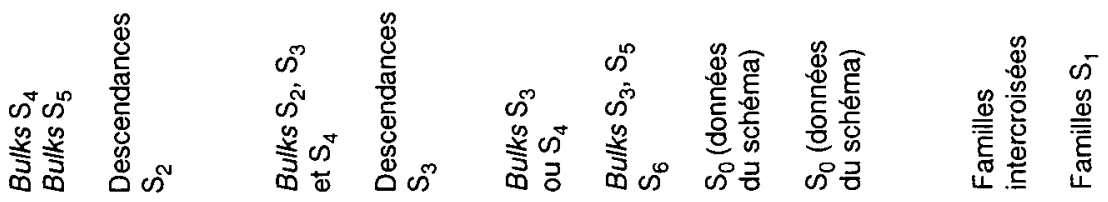

慗

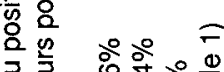

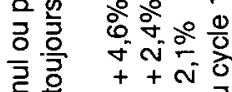

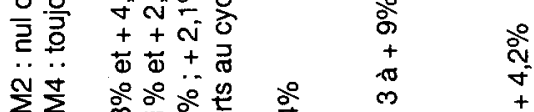

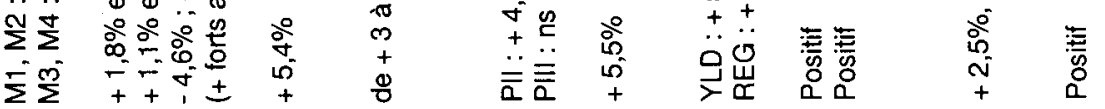
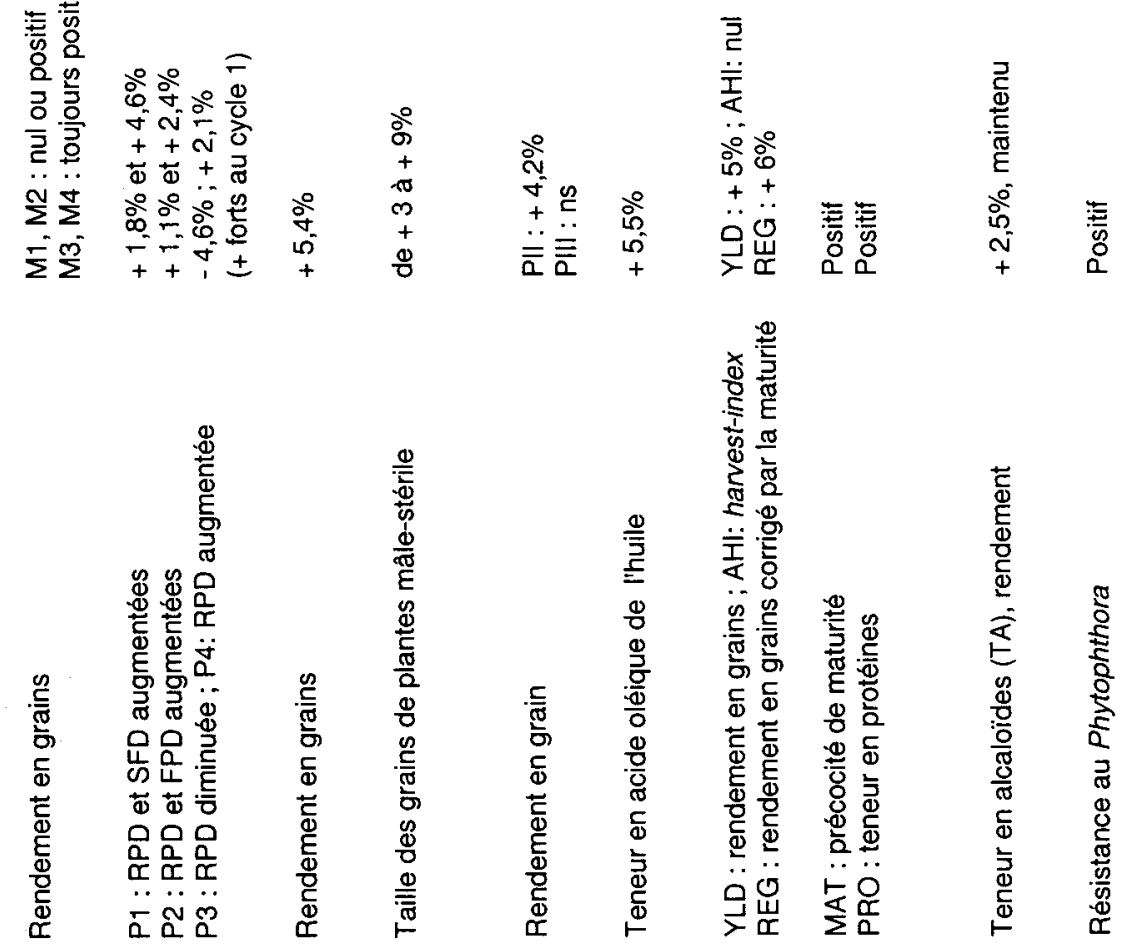

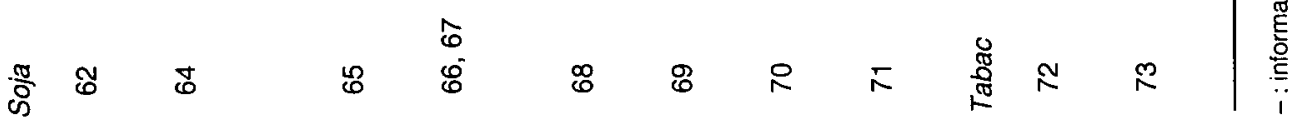


à raison d'une plante par famille et évaluent les populations intercroisées. Une évaluation est réalisée sur des générations plus avancées : Brabant et al (1991) observent des familles $S_{7}$ ou $S_{5}$ extraites par SSD de chaque cycle. Cela permet alors de se rapprocher de la valeur en lignées des populations des différents cycles. Le calcul du progrès peut également poser des problèmes. Hanson (1992), ayant réalisé 3 années d'évaluation dans la population de départ, pour le choix des lignées à intercroiser, compte le passage de la population totale aux individus sélectionnés comme le premier cycle. De plus, c'est durant cette étape que la réponse est la plus forte. La comparaison du progrès calculé ici avec ceux calculés dans les autres expériences nous semble difficile.

Le nombre de familles observées pour évaluer chaque cycle varie d'une trentaine à une centaine. Lorsqu'il s'agit des familles sélectionnées, elles sont naturellement moins nombreuses : 12 pour Hanson (1992) ou 30 chez Guimaraes et Fehr (1989), par exemple.

Les auteurs s'efforcent d'évaluer les familles dans 2 lieux ou bien 2 années de suite, et beaucoup groupent les descendances des familles en bulks pour obtenir suffisamment de graines et réaliser des parcelles assez grandes. Cependant, les conditions d'évaluation du progrès sont souvent plus proches de celles de la sélection que des conditions de culture de l'espèce. Par exemple, toutes les expériences sur l'avoine sont réalisées avec des parcelles en poquets largement espacées. Sur le tabac, Legg et Nielsen (1992) évaluent le progrès sur des parcelles de 10 plantes. Pour illustrer ce point, on peut regarder les résultats de Schipper et Frey (1991b et 1992). Ils pratiquent la même sélection pour la teneur en huile, mesurée au champ (R1) et en serre (R2). La réponse à la sélection (étudiée au champ) n'est significative que pour R1. La sélection pratiquée en serre revient à une sélection indirecte et son efficacité dépend à la fois de l'héritabilité du caractère mesuré en serre et de la corrélation "serre-champ". Schipper et Frey (1991a) montrent que l'héritabilité de la teneur en huile en serre est inférieure ou égale à celle du même caractère au champ, et que la corrélation génétique "serre-champ» est égale au maximum à 0,87. Rose et al (1992) observent de grandes différences dans les estimations du progrès: le progrès mesuré sur des bulks $S_{3}$ dans le lieu de la sélection est plus de 2 fois plus fort que celui estimé sur bulks $\mathrm{S}_{4}$ dans 5 lieux l'année suivante.
On voit ici l'importance d'une évaluation du progrès en conditions proches des conditions de culture commerciale. Plus les conditions d'évaluation sont proches des conditions de sélection, plus le progrès calculé a des chances d'être élevé. Par exemple, les progrès enregistrés par Werner et Wilcox (1990) et Xu et Wilcox (1992) sont mesurés directement pendant la sélection sur plantes isolées. Ces progrès risquent de ne renseigner que très imparfaitement sur le progrès réel en culture normale.

\section{Caractères non sélectionnés, réponses corrélatives}

L'effet de la sélection sur d'autres caractères non pris en compte a été abondamment étudié. L'expérience a montré, en effet, que des réponses corrélatives négatives pouvaient annuler complètement le progrès sur le caractère sélectionné (Kervella et al, 1991).

Des réponses négatives couramment obtenues sont, par exemple, la diminution du rendement lorsque I'on sélectionne pour la concentration en certaines composantes des graines. Schipper et Frey (1991b et 1992) l'observent en sélectionnant la teneur en huile chez l'avoine, Burton et al (1983) en sélectionnant la teneur en acide oléique de l'huile chez le soja, et Carter et al (1982) en sélectionnant sur la teneur en protéines des graines de soja. L'expérience de Matzinger et al (1989) sur le tabac montre que le fait de prendre en compte le rendement dans la sélection permet de maintenir son niveau tout en progressant sur le caractère principal. D'autres effets sont souvent observés par les sélectionneurs : évolution de la précocité, de la hauteur ou du poids de 1000 grains, lorsque l'on sélectionne pour le rendement ou la teneur des graines en certaines composantes (Guimaraes et Fehr, 1989 ; Rose et al, 1992 ; Burton et al, 1983 et 1990 ; Werner et Wilcox, 1990 ; McFerson et Frey, 1990, 1991 et 1992 ; Branson et Frey, 1989a et b ; Delaney et Bliss, 1991a et b). À cet égard, les résultats de Werner et Wilcox (1990) sont très concluants. Ils sélectionnent le rendement en grains chez le soja, d'une part sans prendre en compte la maturité, d'autre part en le corrigeant par celle-ci. Pour des niveaux comparables de progrès sur le rendement, ils obtiennent dans le premier cas une réponse corrélative significative sur la maturité et, dans le second cas, aucun effet. Évidemment, cela est aussi vrai dans l'autre sens : la sélection pour la 
précocité de Xu et Wilcox (1992) a des effets sur le rendement. On observe également des réponses du type «diminution de la teneur d'une composante des graines» lorsque l'on sélectionne sur une autre composante ( $\mathrm{Xu}$ et Wilcox, 1992). Rose et al (1992) présentent un résultat original : la résistance à Phytophthora augmente avec la sélection sur le rendement chez le soja. Les auteurs attribuent cet effet aux caractéristiques du lieu où a été effectuée la selection : le site est particulièrement infesté par ce champignon et les individus peu résistants donnent des rendements catastrophiques.

L'ensemble des résultats semble bien confirmer la nécessité de prendre en compte tous les caractères qui interviennent dans l'élaboration de la valeur agronomique. Cela justifie les expériences de sélection sur index (Thomas et al, 1991b ; Brabant et al, 1991 ; Marocco et al, 1992) ou celles contrôlant par niveaux indépendants la valeur de différents caractères (Frey et al, 1988 ; McFerson et Frey, 1990, 1991 et 1992 ; Branson et Frey, 1989a et b ; Schipper et Frey, 1991b et 1992 ; Guimaraes et Fehr, 1989 ; Matzinger et al, 1989).

\section{Évolution de la variabilité génétique de la population (tableau III)}

De nombreux auteurs s'intéressent à la variabilité génétique encore disponible après plusieurs cycles de sélection. Cela permet d'évaluer l'intérêt du schéma à plus long terme et les perspectives de poursuite de la sélection. Là encore, les résultats présentés sont très hétérogènes quant à leur nature. II peut s'agir d'une estimation de la variance génétique ou de l'héritabilité des caractères (McFerson et Frey, 1992 ; Branson et Frey, 1989a et b ; Schipper et Frey, 1992 ; Brabant et al, 1991 : Marocco et al, 1992 ; Rose et al, 1992; Burton et al, 1990 ; Matzinger et al, 1989), mais aussi simplement de la variance phénotypique estimée (Delaney et Bliss, 1991a ; Thomas et al, 1991b ; Werner et Wilcox, 1990 ; Xu et Wilcox, 1992), ce qui est tout de même moins précis. Même dans le cas de variances génétiques, les comparaisons peuvent être difficiles, si ce ne sont pas les mêmes niveaux de consanguinité qui servent à évaluer chaque cycle: par exemple, McFerson et Frey (1992) comparent les variances génétiques entre bulks $S_{3}$ issus de $S_{0}$ du cycle 0 et familles $S_{1}$ du cycle 3 . Ces valeurs ne sont comparables que si la variance est purement additive.
Quel que soit le mode d'évaluation de la variabilité, la plupart des auteurs observent une diminution de celle-ci, parfois même assez importante (Burton et al, 1990 : diminution de 90\% dans PII; Delaney et Bliss, 1991a, ainsi que Rose et al, 1992 : diminution de $80 \%$ ). Il y a quelques cas où elle semble se maintenir (McFerson et Frey, 1992; Werner et Wilcox, 1990 ; Xu et Wilcox, 1992). II semble difficile de relier la diminution de variabilité à l'intensité de sélection ou au nombre d'individus gardés, et ce d'autant plus que les auteurs ne donnent pas toujours l'information à ce sujet.

Par ailleurs, nous avons vu que la réponse à la sélection dans le cas où 4 cycles au moins avaient été réalisés ne diminuait pas: cela est une indication a posteriori d'un certain maintien de la variabilité génétique dans la population durant les cycles déjà réalisés. Le seul élément dont nous disposons (voir plus haut) est que, pour un même schéma réalisé sur 2 populations de bases génétiques différentes, le progrès est plus faible dans la population à base étroite, et qu'à la limite il devient nul (Burton et al, 1990). Dans ce cas, la variabilité génétique, faible dès le départ, semble bien avoir été épuisée. De façon générale, il semble bien y avoir une diminution de la variabilité à la suite de la sélection, mais la variabilité reste suffisante pour assurer un progrès génétique continu, sauf dans quelques rares cas où l'on partait d'une base génétique très étroite.

\section{CONCLUSION}

Les expériences de sélection récurrente sur des espèces autogames présentent différents aspects communs au niveau des schémas. Tout d'abord, de réels progrès ont été réalisés sur la durée du cycle : la plupart des schémas tiennent en 1 an ou 2. Cela a pu se faire grâce à une sélection très précoce, ainsi qu'à la maîtrise des générations dérobées. Certains problèmes apparaissent cependant avec la sélection précoce. On se trouve généralement en conditions de sélection indirecte par rapport à l'expression du ou des caractères en conditions de culture commerciale. Il devient alors important d'évaluer le progrès dans les conditions plus proches de celles de la grande culture que celles de la sélection ; ce qui n'est pas toujours fait dans les expériences décrites. De plus, la sélection est faite sur des individus encore très hétérozygotes et, éventuellement, sur des descendances très hé- 
térogènes; cela peut compliquer la sélection ainsi que l'intercroisement. Là encore, l'évaluation est importante : elle devrait être faite sur des lignées ou des familles hautement consanguines pour donner une idée du progrès sur l'aptitude de la population à donner de bonnes lignées pures. À ce propos, on ne peut que regretter qu'il n'y ait aucune nouvelle expérience de sélection récurrente sur lignées obtenues par haplodiploïdisation.

Un second point est le recentrage autour de 5 à 10 du nombre de génotypes utilisés pour former la population de départ, ainsi qu'une limitation au niveau des origines. Les populations formées à partir de 2 parents ont tendance à disparaître. C'est un bon point, car on a vu qu'un épuisement de la variabilité au cours des premiers cycles peut remettre en cause l'efficacité de la sélection dans ces cas-là. Cependant, même pour les autres populations, il n'est pas évident que le progrès puisse se maintenir à long terme : en effet, une diminution de la variabilité durant la sélection a souvent été mise en évidence.

On a noté également que des efforts avaient été portés sur l'intercroisement pour former la population de départ. L'utilisation de stérilités mâles apparaît intéressante, mais son utilisation semble restreinte au soja, pour lequel les expérimentateurs montrent certaines ouvertures avec, par exemple, des expériences de sélection pour le rendement malgré la disjonction du caractère mâle-stérile.

Une critique commune à de nombreux schémas reste la prise en compte d'un faible nombre de caractères, voire d'un seul, dans la sélection. Bien que les auteurs aient tous conscience des problèmes posés par des réponses corrélatives négatives, peu prennent en compte l'ensemble de la valeur agronomique ou même simplement quelques caractères supplémentaires.

L'ensemble des résultats est intéressant pour les sélectionneurs. Les schémas se rapprochent des besoins et des conditions de l'amélioration des populations pour la création variétale et, de façon plus fondamentale, certaines expériences fournissent de nouveaux critères de sélection (plus ou moins directs) pour des caractères physiologiques plus complexes et donnent des informations sur les relations entre ceux-ci.

\section{RÉFÉRENCES}

Brabant P, Kervella J, Doussinault G, Picard E, Rousset $M$ (1991) Influence du premier cycle de sélec- tion récurrente à une population de blé tendre d'hiver. agronomie 11, 473-482

Branson CV, Frey KJ (1989a) Recurrent selection for groat oil content in oats. Crop Sci 29, 1382-1387

Branson CV, Frey KJ (1989) Correlated response to recurrent selection for groat-oil content in oats. Euphytica 43, 21-28

Burton JW, Brim CA (1981) Registration of two soybean germplasm populations. Crop Sci 21, 801

Burton JW, Wilson RF, Brim CA (1983) Recurrent selection in soybean. IV. Selection for increased oleic acid percentage in seed oil. Crop Sci 23, 744-747

Burton JW, Koinange EMK, Brim CA (1990) Recurrent selfed progeny selection for yield in soybean using genetic male sterility. Crop Sci 30, 1222-1226

Carter TE Jr, Burton JW, Brim CA (1982) Recurrent selection for percent protein in soybean seed. Indirect effects on plant $\mathrm{N}$ accumulation and distribution. Crop Sci 22, 513-519

Choo TM, Christie BR, Reinbergs E (1979) Doubled haploids for estimating genetic variances and a scheme for population improvement in selfpollinating crops. Theor Appl Genet 54, 267-271

Delaney DE, Bliss FA (1991a) Selection for increased percentage phaseolin in common bean. 1. Comparison of selection for seed protein alleles and $\mathrm{S} 1$ family recurrent selection. Theor App/ Genet 81, 301-305

Delaney DE, Bliss FA (1991b) Selection for increased percentage phaseolin in common bean. 2. Changes in frequency of seed protein alleles with $\mathrm{S} 1$ family recurrent selection. Theor App/ Genet 81, 306-311

Dogget H (1972) Recurrent selection in sorghum populations. Heredity 28, 9-29

Frey KJ, McFerson JK, Branson CV (1988) A procedure for one cycle of recurrent selection per year with spring-sown small grains. Crop Sci 28, 855856

Gallais A (1990) Quantitative genetics of doubled haploid populations and application to the theory of line development. Genetics 124, 199-206

Guimaraes EP, Fehr WR (1989) Alternative strategies of recurrent selection for seed yield of soybean. Euphytica 40, 111-120

Habgood RM, Rafique Uddin M (1984) The effect of genetic background on grain shrivelling in lys 3 barley and its possible modification by a recurrent selection programme. Z Pflanzenzücht 93, 65-77

Hanson WD (1985) Association of seed yield with partitioned lengths of the reproductive period in soybean genotypes. Crop Sci 25, 525-529

Hanson WD (1992) Phenotypic recurrent selection for modified reproductive period in soybean. Crop Sci 32, 968-972

Jacquard $P$ (1975) Concurrence intraspécifique et potentialités de rendement. Ann Amélior Plant (Paris) 25 (1), 3-24

Kervella J, Goldringer I, Brabant P (1991) Sélection récurrente chez les autogames pour l'amélioration 
des variétés lignées pures: une revue bibliographique. agronomie 11, 335-352

Knapp SJ, Cox TS (1988) S1 family recurrent selection in autogamous crops based on dominant genetic male sterility. Crop Sci 28, 227-231

Legg PD, Nielsen MT (1992) Genetic variation for agronomic characters in a burley tobacco synthetic following recurrent selection for increased black shank resistance. Plant Breed 108, 185-189

Leemans J (1992) Genetic engineering for fertility control. In: Reproductive biology and plant breeding. XIIIth EUCARPIA Congr, 6-11 juillet 1992, 101-106

Marocco A, Cattivelli L, Delogu G, Lorenzoni C, Stanca AM (1992) Performance of S2 winter barley progenies from original and improved populations developed via recurrent selection. Plant Breeding $108,250-255$

Matzinger DF, Wernsman EA, Weeks WW (1989) Restricted index selection for total alkaloids and yield in tobacco. Crop Sci 29, 74-77

May L, Van Sanford DA (1992) Selection for early heading and correlated response in maturity of soft red winter wheat. Crop Sci 32, 47-51

McFerson JK, Frey KJ (1990) Three selection strategies to increase protein yields in oats. $J$ Genet Breed 44, 39-48

McFerson JK, Frey KJ (1991) Recurrent selection for protein yield of oat. Crop Sci 31, 1-8

McFerson JK, Frey KJ (1992) Correlated response to selection for protein yield in oats after three cycles of recurrent selection. Plant Breed 108, 149-161

Patel JD, Reinbergs E, Fejer SO (1985) Recurrent selection in doubled-haploid population of barley (Hordeum vulgare L). Can J Genet Cytol 27, 172-177

Piper TE, Fehr WR (1987) Yield improvement in a soybean population by utilizing alternative strategies of recurrent selection. Crop Sci 27, 172-178

Rose JL, Butler DG, Ryley MH (1992) Yield improvement in soybeans using recurrent selection. Aust $J$ Agric Res 43, 135-144

Saur L, Trottet M (1992) Héritabilté de la résistance à la fusariose de l'épi et sélection récurrente dans une population de blé tendre. agronomie 12, 297-302

Schipper H, Frey KJ (1991a) Selection for groat-oil content in oats grown in field and greenhouse. Crop Sci 31, 661-665
Schipper H, Frey KH (1991b) Observed gains from three recurrent selection regimes for increased groat-oil content of oat. Crop Sci 31, 1505-1510

Schipper H, Frey KJ (1992) Responses in agronomic traits associated with three recurrent selection regimes for groat-oil content in oats. Plant Breed $108,302-313$

Snape JW, Ouyang JW, Parker BB, Jia SE (1992) Evidence for genotypic selection in wheat during the development of recombinant inbred lines by anther culture and SSD. J Genet \& Breed 46, 167172

Sorrells ME, Fritz SE (1982) Application of a dominant male-sterile allele to the improvement of selfpollinated crops. Crop Sci22, 1033-1035

Stelling D, Ismail MN, Ebmeyer E, Frauen M, Röbbelen $G(1990)$ Selection in early generations of dried peas, Pisum sativum L. III. Plot size and plot type. Plant Breed 105, 238-247

Suenaga K, Nakajima K (1993) Segregation of genetic markers among wheat doubled haploid lines derived from wheat maize crosses. Euphytica 65, 145-152

Thomas G, Rousset M, Pichon M, Trottet M, Doussinault G, Picard E (1991a) Méthodologie de l'amélioration du blé tendre (Triticum aestivum $L$ ). I. Création par croisements et analyse d'une population artificielle à 16 parents, base de cette étude méthodologique. agronomie 11, 359-368

Thomas G, Doussinault G, Trottet M (1991b) Méthodologie de l'amélioration du blé tendre (Triticum aestivum L). II. Étude et analyse de deux premiers cycles de sélection récurrente. agronomie 11, 457472

Tinius CN, Burton JW, Carter TE Jr (1991) Recurrent selection for seed size in soybean. I. Response to selection in replicate populations. Crop Sci 31, 1137-1141

Tinius CN, Burton JW, Carter TE Jr (1992) Recurrent selection for seed size in soybean. II. Indirect effects on seed growth rate. Crop Sci 32, 1480-1483

Werner BK, Wilcox JR (1990) Recurrent selection for yield in Glycine max using genetic male sterility. Euphytica 50,19-26

Xu H, Wilcox JR (1992) Recurrent selection for maturity and percent seed protein in Glycine max based on So plant evaluation. Euphytica $62,51-57$ 